\title{
Biomedical Education: A Summary Report of the Biorisk Management Curriculum Development Workshop
}

\author{
Subhash Janardhan Bhore \\ Department of Biotechnology, Faculty of Applied Sciences, AIMST University, Bedong-Semeling Road, Semeling 08100, Kedah, MALAYSIA.
}

\section{Dear Editor}

The safety in general and biological safety (biosafety) in particular is an important international issue. Member states of the United Nations (UN) have developed their national biosafety policies to address biosafety (and biosecurity) issues in line with the international agenda. The Biorisk Management (BRM) is a relatively new domain in biomedical sciences and biotechnology. It provides the strategic framework for action for the laboratory biosafety and biosecurity (along with bioethics). ${ }^{1-2}$ In fact, BRM is very vital for the global safety and security. Therefore, the BRM curriculum should be developed and incorporated into biomedical sciences and biotechnology education programmes of every country to prepare next generations to meet the biosafety, biosecurity and bioethics challenges.

Through the Cooperative Biological Engagement Program, the Sandia National Laboratories (USA) is providing 'Global BRM Curriculum (GBRMC)' based on the international best practices such as CWA 15793 and WHO biosafety and biosecurity guidance. ${ }^{2-3}$ The Sandia National Laboratories is also involved in conducting 'BRM Curriculum Development Workshops' for academicians with the aim to enhance their academic leadership in BRM. This article is based on the five-day 'BRM Curriculum Development Workshop' under the aegis of 'Biosecurity Engagement Program, held on $26^{\text {th }}$ February $-2^{\text {nd }}$ March 2018, at the JW Marriott Hotel, Kuala Lumpur, Malaysia. Twelve participants who have prior knowledge of BRM concepts [International Federation of Biosafety Associations (IFBA) Certified Professionals] and undergraduate level of biomedical or biotechnological sciences were chosen to participate in this workshop. The goal of the workshop was to empower academicians with the skills, tools, and confidence to establish a sustainable BRM education in existing curricula at their university or institute. This article highlights the essence of the BRM Curriculum Development Workshop.

At the beginning of the workshop, facilitators, Pinard W. and Shurdhi I. (Sandia National Laboratories, USA) gave an overview of BRM and highlighted the importance of implementing it in universities curricula. Pinard gave a comprehensive overview of the GBRMC and highlighted that it is a reliable educational resource for developing BRM curriculum. The primary mission of the GBRMC is to provide trustworthy, wellbranded, well-managed and strategic biosafety and biosecurity training materials anywhere, anytime in a sustainable manner, participants learned. Workshop facilitator underlined that there are more than 40 courses in the GBRMC library for three targeted groups (role-focused) namely, 'Management and Leadership', 'BRM Advisors and Advocates' (e.g., Biosafety Officers, Institutional Biosafety Committee), and 'Laboratory Management and Workforce'. The courses are designed on outcome-based approach and academicians (or BRM trainers) can access the GBRMC library by registering themselves online without any payments and or fees (public access site: http://ibctr.sandia.gov/human_capacity_development/hcd-gbrmc.html). However, the full access to it is only to those who go through the Trainer Development Program, 'The University Curriculum Development Program', or other 'specialised mentorship'. You may note that some elements are available publicly, but the course catalogue is not without training.

In 'Orientation to BRM' session, Pinard highlighted that AMP (Assessment, Mitigation and Performance) is a simple but powerful model for managing biorisks. He also stressed that implementing a comprehensive BRM system is critical to reduce both the safety and security risks associated with biological agents which we use in biological, medical and or biotechnological laboratories. The commitment by top management and a focus on continual improvement is the key to establishing and implementing a successful BRM system, Pinard elegantly emphasised. He also stressed that academicians should make use of the 'CWA 15793', a comprehensive framework developed through international collaboration for managing biorisks. ${ }^{2}$

While delivering an invited talk, 'The Status of BRM in Malaysian Universities', Bhore SJ (AIMST University, Malaysia) highlighted that universities, research institutions and biotech companies in Malaysia that are involved in modern biotechnology research and development ( $R$ and D) need to comply with Malaysian Biosafety Act 2007 and Malaysian Biosafety Regulations-2010. The standalone BRM (and or Laboratory BRM) courses are not common in Malaysian universities curricula; but, the research ethics and biosafety elements are embedded in universities curricula, Bhore underlined his observation. $\mathrm{He}$ also emphasised that to prepare graduates to deal with biosafety and biosecurity challenges and to meet the industry needs; the collective efforts of all stakeholders (from public and private) are needed. Through group exercises and discussion, facilitators trained participants for - how to identify biorisks? What can academicians (workshop participants) do to manage identified risks? Also, what can be done to know that BRM system is working and will continue to work? As a result, participants were habituated with biorisk 'assessment', 'mitigation' and 'performance', the three key components of AMP model for BRM.

After discussing the importance and need of including BRM into existing university or collegiate curricula, participants conducted the gap analysis on their existing curricula to determine when and how to introduce fundamental BRM concepts. The gaps in the course curricula (brought by participants) were identified using questions stated below:

- What level of competence is desired in the targeted learners?

- Is there a problem of lack of knowledge in an essential area and or skill among targeted learners?

For the effective teaching and learning of BRM, facilitators did present a brief overview of the 'ADDIE model' to make academics familiar with the model. The ADDIE model is well-known for its usefulness for the course (or module) developers. Participants were made familiar with the five phases of the ADDIE model namely, analysis, design, 
development, implementation, and evaluation. ${ }^{4}$ While teaching students at university level, the approach, method and practice of teaching adult learners (andragogy) is more effective, facilitators highlighted. In ADDIE model, analysis is the first part and used to know - who is the targeted audience? How to identify the new behavioural outcome? What types of learning constraints exist? What are the delivery options? What are the online andragogical considerations? Moreover, what is the timeline for course/degree programme completion? Similarly, the participants were made mindful of the importance of course design, content development, course or a lecture plan implementation and importance of the evaluation (formative and summative) of the whole process by implementing ADDIE model.

While equipping participants for the BRM curriculum development and its implementation, facilitators highlighted that academics need to take into account - What is the purpose of a curriculum? Whom do we teach? Why do we teach? How to structure material for promoting BRM education? What are the BRM teaching goals? How to use instructional design model to make learning more efficient, effective and less stressful? What type of approaches should be used to keep students engaged and motivated in the classroom? What makes an academic class, training, or workshop 'excellent'? What are the best attributes of an academician for the effective teaching? What makes a student 'effective' at learning? What do we have? Where do we want to go? What factors would impact, influence or limit introduction of teaching BRM in higher education?

During BRM curriculum development, the inclusion of relevant topics is essential. Hence, through group discussions and activities, participants understood the importance of - What should be course objectives? What difference content should make to learners in stipulated time? How will learners (targeted students) be better off for knowing BRM? How will BRM content be organised? What skills will students acquire that will help them in the future? What students will/should remember about BRM? What content targeted students need to know to meet (or perform) the intended outcomes and have an effect on the issue?

In the process of course curriculum development and its implementation, academicians also need to bear in mind the effect and importance of using elements of learning domains. To make all participants clearer, Shurdhi gracefully highlighted that the learning outcomes are sorted into three primary categories namely, Cognitive (Know - Knowledge, Memory), Affective (Feel - Attitude, Thoughts), and Psychomotor (Do - Behavior, skills). She also emphasised that the systematic use of 'Bloom's Taxonomy' needs to be done while designing and implementing the course curriculum. ${ }^{5}$ Group exercises on drafting 'learning outcomes' and 'learning objectives' covering cognitive, affective and psychomotor domains were helpful to participants in understanding the benefits of systematic designing of outcome-based BRM curriculum. Developing a successful outcome-based BRM curriculum involves aligning teaching and assessment methods with the intended learning outcomes of the program, participants learned.

Generally, the teaching staff of universities will not have formal training to teach students. Therefore, academicians need to bear in mind the use of principles of learning and brain-friendly teaching strategies for the benefit of the students. Pinard gave a broad overview of the principles of learning and brain-friendly teaching strategies. He highlighted the importance of various elements such as readiness, exercise, effect, primacy, intensity, freedom, requirement and recency which should be used during BRM classes or activities. He also highlighted that academicians should bear in mind the usefulness of 'Jensen model' for brain-based effective teaching of BRM. ${ }^{6}$ For the effective teaching and learning, academicians also need to understand the 'Maslow's Hierarchy of Needs.7 In this line the, group exercises helped participants to understand the importance of various factors that affect teaching and learning. Some of the essential questions discussed were as follows:

- What might an instructor do to overcome barriers to learning?

- What are factors that contribute in making an excellent learning environment?

- How do physical environments affect our brain?

- What are three simple things every lecturer can do to boost learning in the classroom environment?

Participants were also made aware of the importance of understanding 'memory and recall enhancements' techniques for effective teaching and learning.

For effective teaching (and learning), academicians need to understand students 'sensory styles' [auditory (hearing), visual (seeing) and kinesthetic (moving)], and 'learning styles' namely, reflector (observer), theorist (thinker), activist (feeler), and pragmatist (doer), participants learned while discussing learning styles of the students. The implementation of the BRM lesson plans will be very effective if the academic staff understand teaching principles, and students 'sensory styles' and 'learning styles'.

As a part of the evaluation process, all participants were made familiar with the four levels of impact (namely, reaction, learning, behaviour and results) a curriculum or a programme can make on students. In the process of evaluation, feedback from students and as well as all stakeholders is essential as it can help significantly to improve the curriculum content and programme as a whole. Academicians should also take note of the fact that feedback from students is instrumental to improve teaching style and to become an excellent educator.

Finally, each group containing three participants prepared and presented a lesson plan on a given BRM topic by applying all the techniques learned during the workshop. To let participants explore the usefulness of teaching and training material resources for various BRM courses housed on Sandia National Laboratories Connect Network, the full access to the GBRMC library was given to all participants of the workshop.

To sum up, the workshop was strategic to the participants to fully understand the essential elements of curriculum development. The knowledge and insights gained through workshop will undoubtedly enable participants to develop and implement BRM in their respective institutions of higher learning to educate the medical, biology and biotechnology students. However, the comprehensions highlighted in this report may be helpful to other academicians those are interested in developing and implementing curriculum in their departments, faculties and or universities.

\section{ACKNOWLEDGEMENT}

The author gratefully acknowledges the financial support from the US Department of State's Biosecurity Engagement Program (BEP) and the technical support from the Sandia National Laboratories, USA. The author also wishes to thank the Malaysian Biosafety and Biosecurity Association (MBBA), Malaysia, for the administrative support.

\section{CONFLICT OF INTEREST}

The author declares no conflict of interest.

Note : The views expressed are purely of the author and may not in any circumstances be regarded as stating an official position of the Sandia National Laboratories (USA), the Malaysian Biosafety and Biosecurity Association or any other organisation stated in the article. 


\section{REFERENCES}

1. Rüdelsheim P. CEN Workshop establishes an international Laboratory Biorisk Management Standard. N Biotechnol. 2008;25:117-8.

2. Ref. No.: CWA 15793:2011 D/E/F. CEN Workshop Agreement. CWA 15793. 2011

3. Laboratory Biosafety Manual. $3^{\text {rd }}$ ed. World Health Organization: Geneva, Switzerland. 2004.
4. Molenda M. In search of the elusive ADDIE model. Performance Improvement. 2003;42(5):34-7.

5. Krathwohl DR. A revision of Bloom's taxonomy: An overview. Theory Pract. 2002;41(4):212-8.

6. Jensen E. Teaching with the Brain in Mind, $2^{\text {nd }}$ ed., Association for Supervision and Curriculum Development (ASCD): Alexandria, Virginia. 2005.

7. Maslow AH. A theory of human motivation. Psychol Rev. 1943;50(4):370-96.

Correspondence

Dr. Subhash Janardhan Bhore, Department of Biotechnology, Faculty of Applied Sciences, AIMST University, Bedong-Semeling Road, Semeling 08100,

Kedah, MALAYSIA.

Phone: +60-04-4298176

Email: subhash@aimst.edu.my / subhashbhore@gmail.com DOI: 10.5530/jyp.2018.10.105

Article History: Submission Date : 23-03-2018 ; Revised Date : 02-07-2018; Acceptance Date : 27-07-2018.

Cite this article: Bhore SJ. Biomedical Education: A Summary Report of the Biorisk Management Curriculum Development Workshop. J Young Pharm. 2018;10(4):484-6. 